\title{
Risk assessment of precipitation extremes in northern Xinjiang, China
}

\author{
Jun Yang ${ }^{1,2} \cdot$ Ying Pei $^{1} \cdot$ Yanwei Zhang ${ }^{2,3} \cdot$ Quansheng $\mathrm{Ge}^{2}$
}

Received: 12 September 2016 / Accepted: 31 March 2017 /Published online: 25 April 2017

(C) The Author(s) 2017. This article is an open access publication

\begin{abstract}
This study was conducted using daily precipitation records gathered at 37 meteorological stations in northern Xinjiang, China, from 1961 to 2010. We used the extreme value theory model, generalized extreme value (GEV) and generalized Pareto distribution (GPD), statistical distribution function to fit outputs of precipitation extremes with different return periods to estimate risks of precipitation extremes and diagnose aridity-humidity environmental variation and corresponding spatial patterns in northern Xinjiang. Spatiotemporal patterns of daily maximum precipitation showed that aridityhumidity conditions of northern Xinjiang could be well represented by the return periods of the precipitation data. Indices of daily maximum precipitation were effective in the prediction of floods in the study area. By analyzing future projections of daily maximum precipitation $(2,5,10,30,50$, and 100 years), we conclude that the flood risk will gradually increase in northern Xinjiang. GEV extreme value modeling yielded the best results, proving to be extremely valuable. Through example analysis for extreme precipitation models, the GEV statistical model was superior in terms of favorable analog extreme precipitation. The GPD model calculation results reflect annual precipitation. For most of the estimated
\end{abstract}

Jun Yang

yangjun@1nnu.edu.cn

1 Liaoning Key Laboratory of Physical Geography and Geomatics, Liaoning Normal University, No.850 Huanghe Road Shahekou District, Dalian, Liaoning, China

2 Key Laboratory of Land Surface Pattern and Simulation, Institute of Geographic Sciences and Natural Resources Research, CAS, Beijing, China

3 Jinan University Soft Power Research Centre, University of Jinan, Jinan, Shandong, China sites' 2 and 5-year T for precipitation levels, GPD results were slightly greater than GEV results. The study found that extreme precipitation reaching a certain limit value level will cause a flood disaster. Therefore, predicting future extreme precipitation may aid warnings of flood disaster. A suitable policy concerning effective water resource management is thus urgently required.

\section{Introduction}

Climate change, characterized by global warming and its effect on human society, affects the spatiotemporal characteristics of precipitation and increases the frequency of extreme events, such as floods and droughts (Vörösmarty et al. 2010). According to the fourth IPCC report (Du 2007), significant trends in temperature and precipitation were observed around the world, but with different magnitudes. The impacts of those trends in the mid-term are notable in several aspects. In particular, the stress on hydrology resources is expected to intensify. In this respect, several studies have been carried out to determine the impact on water resources (Arnell 1999; Middelkoop et al. 2001; Reilly et al. 2003; Christensen et al. 2006) and agriculture (Moynagh and Schimmel 1999; Li et al. 2015; Zhang et al. 2016). Precipitation changes, which include a greater number of extreme events and longer dry periods, together with temperature increases that increase evapotranspiration, will have negative impacts on agriculture. Particularly in Southern Europe, these trends could exacerbate the existing conditions in areas already vulnerable to climatic variability, reducing water availability. The Mediterranean area may be particularly sensitive. Some authors reported significant changes in precipitation patterns with decreasing precipitation trends for the Mediterranean (Alpert et al. 2002; Norrant and Douguédroit 2006) and significant changes in 
extreme events, with higher rainfall concentrations in a small number of events, and more frequent and extreme droughts (Easterling 2000; Burt et al. 2015).

The changing properties of precipitation extremes have received increasing public attention both in China and the rest of the world (Ge et al. 2016). Since the 2000s, China has experienced a high frequency of floods (Ren et al. 2000; Yan and Yang 2000; Lodh and Raghava 2014). For example, there was torrential rain in Beijing on 21 July 2012 and flooding in Nanjing on 2 June 2015. Li et al. (2015) indicated that in China, there is less co-occurrence of consecutive wet and dry days, and more joint extreme heavy precipitation events with meteorological, public safety, and economical implications, involving less risk of flood and drought co-occurrence in the same year, but higher risk of floods. Li et al. (2011) indicated that flood disasters have increased in response to the higher frequency of intense precipitation events and consequent amplification of their concentration indices and precipitation concentration. Zhang et al. (2015) showed that indices representing temporal variations of regional heavy precipitation display strong inter-decadal variability, with limited evidence of long-term trends. Such indicators vary markedly depending on precipitation type, season, and region. Analysis of precipitation extremes in Xinjiang, western China, also revealed increasing precipitation variability and high-intensity precipitation (Zhang et al. 2012). The overall amount of precipitation has barely changed, though its intensity and frequency has increased.

In this paper, the extreme precipitation in the northern region is used as a research example to show that risk analysis of extreme precipitation can improve the future diagnosis of flood risk, variability, and spatial pattern in Xinjiang, China. It is hoped that the results of this study can provide reference points for global climate change and provide some decisionmaking value for the prevention of disasters caused by extreme climate events.

\section{Study area}

The northern Xinjiang area extends from $42^{\circ}$ to $50^{\circ} \mathrm{N}$, and $79^{\circ}$ to $92^{\circ} \mathrm{E}$ (Fig. 1), enclosing an area of more than $398,456 \mathrm{~km}^{2}$, one twentieth of the total size of China. The northern region includes Changji and Boertala Prefectures, Urumchi, Kelamayi, Shihezi, and Kuitong Cities, and the Yili, Tacheng, and Aletai Regions. Situated deep in the interior of Asia and unaffected by oceanic air currents, the northern Xinjiang Uygur Autonomous Region experiences a typical continental climate, with highly fluctuating temperature, significant differences in diurnal temperature amplitude, abundant sunshine, intense evaporation, and little precipitation. The mean annual temperature of Xinjiang is $8{ }^{\circ} \mathrm{C}$; the hottest month is July, averaging at about $25{ }^{\circ} \mathrm{C}$, and the coldest is

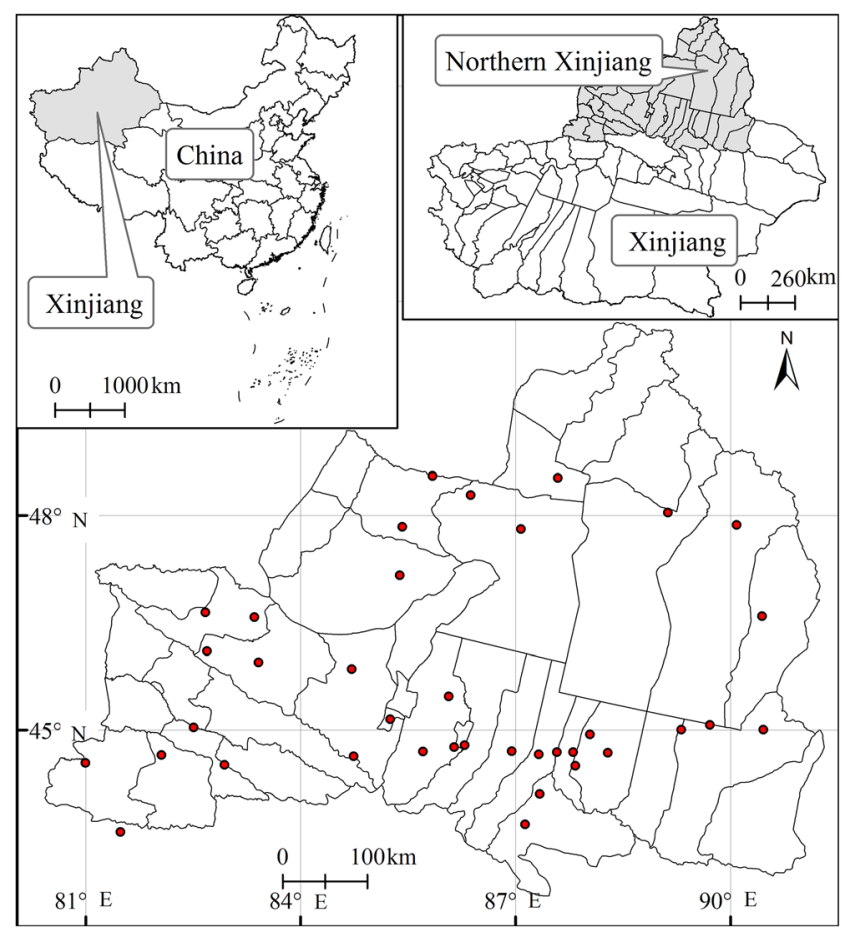

Fig. 1 Region of focus and observation stations. The map was generated using ArcGIS 10.2

January, averaging at $-20{ }^{\circ} \mathrm{C}$ in the north. The mean annual snow depth is $60 \mathrm{~cm}$, reaching a maximum of $1-2 \mathrm{~m}$ in the mountainous areas.

\section{Data and methodology}

\subsection{Data sources}

The data used in the study were daily precipitation series at 37 observatory stations in North Xinjiang, and were provided by the National Climatic Centre of China, China Meteorological Administration (shown in Fig. 1) for the period from 1 January 1961 to 31 December 2010. This institution performed quality control of the dataset prior to its release, and homogeneous detection for the dataset was also done (Li et al. 2011). In total, missing data accounts for $0.05 \%$ of the data series. The station data used in this study were screened for missing values, and only those stations with data records that were at least 95\% complete for the period of 1961-2010 were included in our analysis. The missing data were interpolated using a simple linear correlation method between their neighboring stations. Finally, 37 stations, whose locations are shown in Fig. 1, were chosen for this study.

The climate stations report maximum daily precipitation based on annual maximum daily precipitation. To analyze the maximum daily precipitation through daily precipitation 
Table 1 Summary of annual maximum daily precipitation

\begin{tabular}{|c|c|c|c|c|}
\hline Site & Average (mm) & Standard deviation & Minimum (mm) & $\operatorname{Maximum}(\mathrm{mm})$ \\
\hline Alashankou & 17.39 & 6.81 & 8.00 & 41.20 \\
\hline Aletai & 12.78 & 5.72 & 3.80 & 33.10 \\
\hline Beitashan & 22.67 & 11.78 & 9.40 & 66.90 \\
\hline Bole & 21.08 & 7.86 & 8.60 & 41.70 \\
\hline Buerjin & 14.32 & 6.42 & 5.00 & 34.00 \\
\hline Caijiahu & 15.07 & 5.39 & 7.10 & 27.00 \\
\hline Changji & 19.81 & 6.94 & 10.30 & 43.40 \\
\hline Daxigou & 27.58 & 7.51 & 14.30 & 40.30 \\
\hline Ermin & 20.74 & 7.37 & 9.80 & 44.40 \\
\hline Fuhai & 13.76 & 5.78 & 4.50 & 33.20 \\
\hline Fukanng & 26.89 & 11.51 & 6.10 & 64.00 \\
\hline Fuyun & 18.03 & 7.87 & 7.60 & 41.90 \\
\hline Habahe & 17.50 & 7.81 & 6.20 & 54.00 \\
\hline Hebusaike & 18.92 & 10.69 & 6.80 & 61.50 \\
\hline Hutubi & 18.60 & 7.10 & 8.40 & 38.50 \\
\hline Jimunai & 15.68 & 5.67 & 7.90 & 35.00 \\
\hline Jimushaer & 22.62 & 8.41 & 10.50 & 58.20 \\
\hline Jinghe & 13.05 & 5.86 & 5.60 & 40.10 \\
\hline Kelamayi & 15.38 & 7.70 & 5.20 & 40.50 \\
\hline Manasi & 19.30 & 7.19 & 8.20 & 41.80 \\
\hline Miquan & 27.43 & 8.38 & 11.70 & 45.40 \\
\hline Mosuowan & 14.00 & 6.69 & 6.60 & 37.50 \\
\hline Mulei & 31.99 & 10.01 & 16.80 & 75.90 \\
\hline Paotai & 14.23 & 5.25 & 6.50 & 33.70 \\
\hline Qitao & 21.26 & 9.06 & 9.70 & 58.40 \\
\hline Qinghe & 17.93 & 7.52 & 6.50 & 49.50 \\
\hline Shawan & 18.64 & 5.59 & 10.00 & 36.00 \\
\hline Shihezi & 19.32 & 6.73 & 9.70 & 39.20 \\
\hline Tacheng & 23.98 & 9.50 & 7.40 & 56.90 \\
\hline Tianchi & 54.24 & 22.80 & 24.60 & 131.70 \\
\hline Tuoli & 19.79 & 6.22 & 9.20 & 32.10 \\
\hline Wenquan & 16.89 & 10.85 & 0.99 & 39.10 \\
\hline Urumuqi & 20.50 & 9.17 & 3.80 & 40.50 \\
\hline Wusu & 18.53 & 7.34 & 7.30 & 44.10 \\
\hline Xiaoquzi & 36.11 & 9.06 & 20.50 & 58.20 \\
\hline Yining & 21.88 & 8.54 & 11.20 & 62.90 \\
\hline Yumin & 19.99 & 5.73 & 10.70 & 35.50 \\
\hline
\end{tabular}

over the study period and area (Table 1), extreme value theory (EVT) was used. To reveal maximum daily precipitation, scatter diagrams were used as examples of the sites (Beitashan, Yining, Urumqi, and Habahe).
Table 2 List of distributions used in this study

\begin{tabular}{lll}
\hline Distribution & Probability density function, $f(x)$ & Quantile function, $Q(F)$ \\
\hline GEV & $\frac{1}{\alpha}\left\{1-\kappa \frac{(\chi-\varepsilon)}{\alpha} \alpha\right\}^{\frac{1}{\kappa}-1} \exp \left[-\left\{1-\kappa \frac{(\chi-\varepsilon)}{\alpha} \alpha\right\}^{\frac{1}{\kappa}}\right]$ & $\varepsilon+\frac{\delta}{\kappa}\left[1-\{-\ln (F)\}^{\kappa}\right]$ \\
GPD & $\frac{|\alpha|}{\Gamma(\kappa)}\{\alpha(\chi-\varepsilon)\}^{\kappa-1} \exp \{-\alpha(\chi-\varepsilon)\}$ & $\varepsilon+\frac{\delta}{\kappa}\left\{1-(1-F)^{\kappa}\right\}$ \\
\hline
\end{tabular}


Fig. 2 Annual maximum daily precipitation recorded in $\mathbf{a}$ Beitashan, b Habahe, c Urmuqi, and d Yining from 1961 to 2010

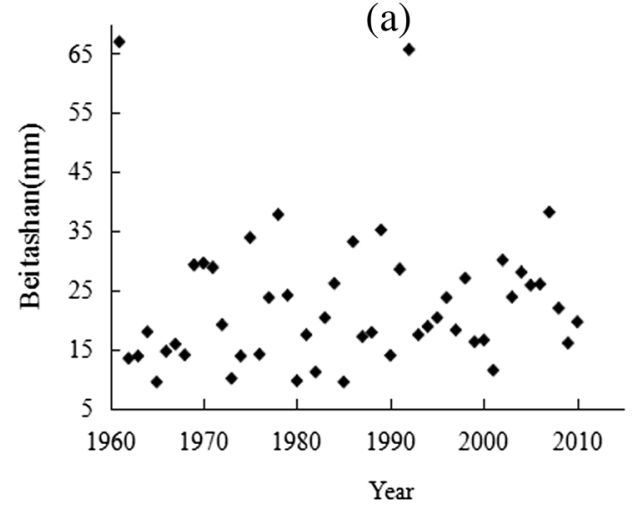

(c)

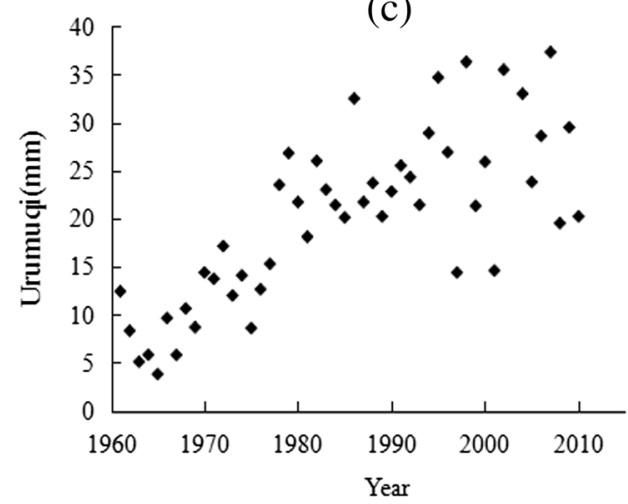

(b)

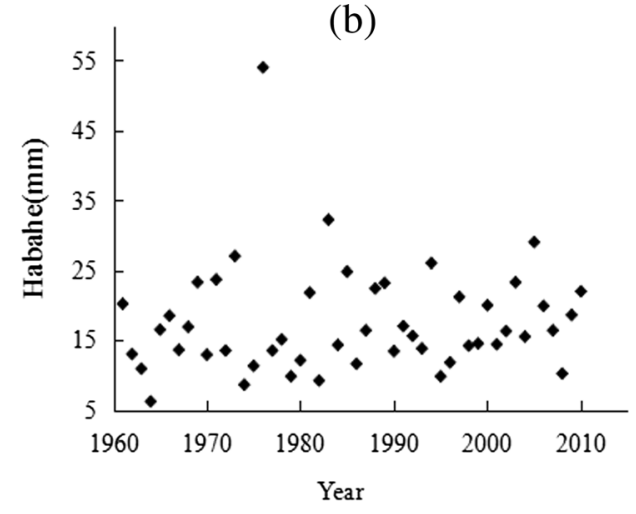

(d)

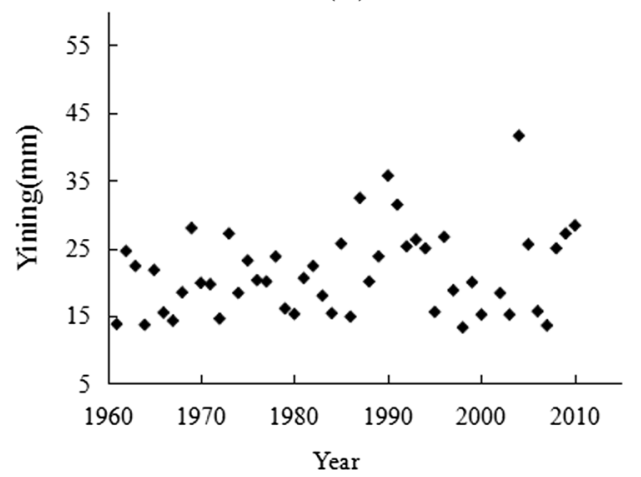

\subsection{Data processing methodologies}

In order to describe the behavior of extreme rainfall at a particular area (North Xinjiang), it is necessary to identify the distribution(s) that best fits the data. In this study, we use three parameter extreme value distributions (generalized extreme value, generalized Pareto), which are considered to be the best-fitting probability distribution function to extreme precipitation data. In probability theory and statistics, the generalized extreme value (GEV) distribution is a family of continuous probability distributions developed within extreme value theory to combine the Gumbel, Fréchet, and Weibull families, also known as type I, II, and III extreme value distributions (Hosking and Wallis 2005). In statistics, the generalized Pareto distribution (GPD), a family of continuous probability distributions, is often used to model the tails of other distributions (Hosking and Wallis 1987), shown in Table 2. Details on these distributions can be found in the works of Hosking and Wallis (2005) and Saghafian et al. (2014). (a)

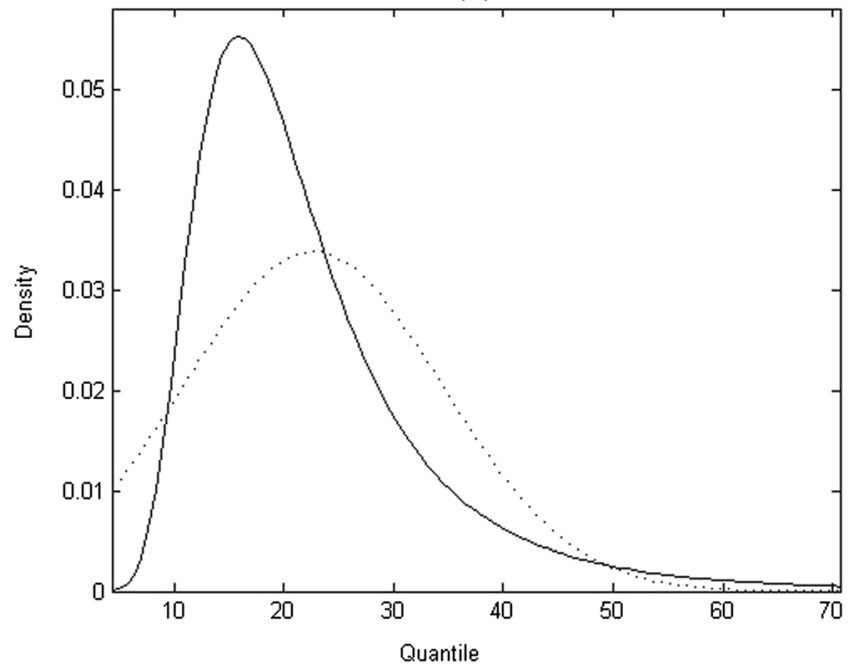

(b)

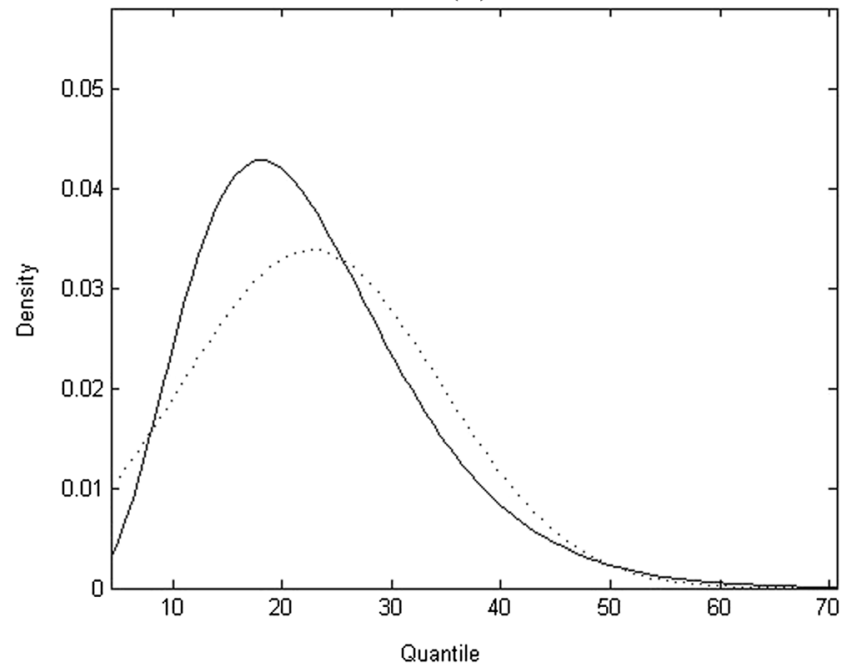

Fig. 3 Fitted (solid line) and non-parametric (dotted line) densities for a model 1 (left) and b model 2 (right) concerning Beitashan 
(a)

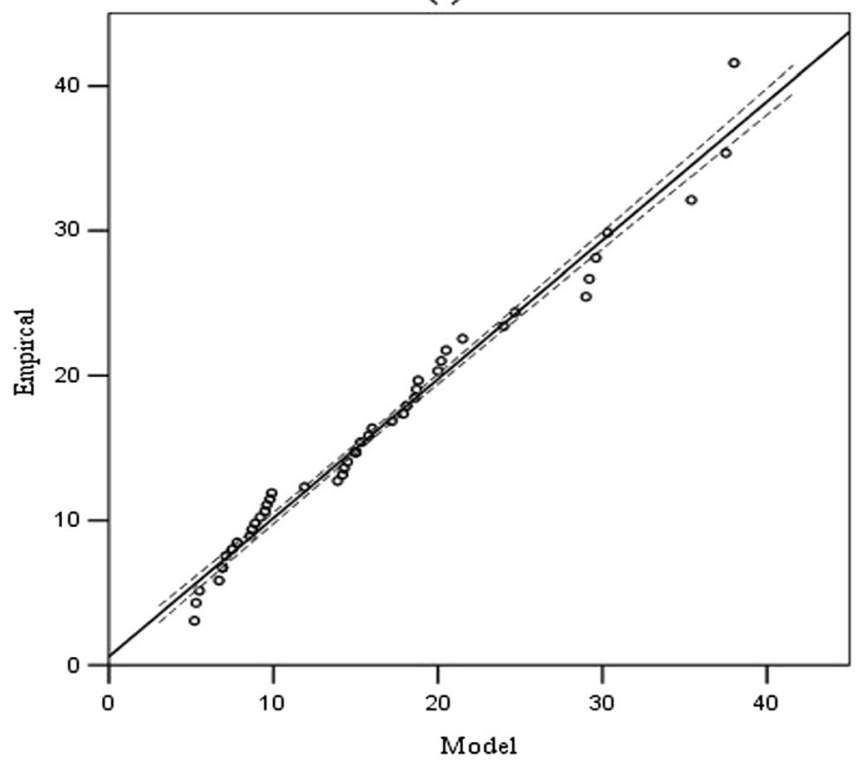

(b)

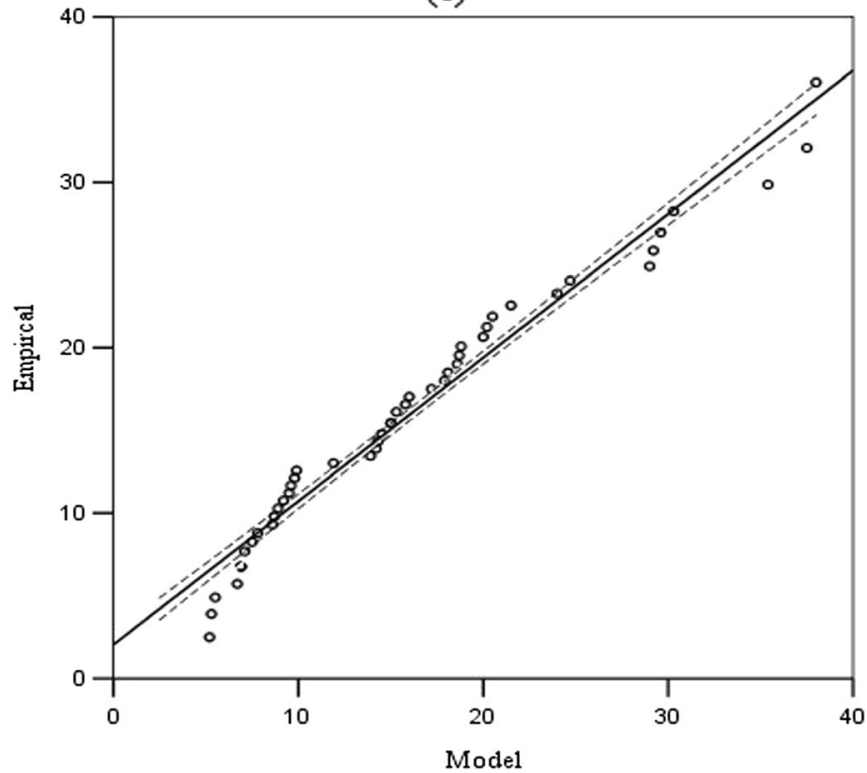

Fig. 4 QQ plot with simulated 95\% confidence intervals for a model 1 and $\mathbf{b}$ model 2 concerning Beitashan

\section{Results and discussion}

\subsection{GEV fitting}

We used the established GEV extreme value model. The theory and approaches are applicable to distributions of extreme minima by analyzing the variable $X$ (Bonacci 1991; Embrechts et al. 1997). The cumulative distribution function (CDF) of the GEV is given by

$F(x)=\exp \left\{-\left(1+\kappa \frac{x-\zeta}{\beta}\right)^{-\frac{1}{\kappa}}\right\}$.

Here, $1+\frac{\kappa(x-\zeta)}{\beta}>0$, and $\varsigma, \beta$, and $\kappa$ represent the position, scale, and shape parameters. If $\kappa=0$, then

$F(x)=\exp \left\{-\exp \left(\frac{x-\varsigma}{\beta}\right)\right\}$.

when $\kappa=0, \kappa>0$, and $\kappa<0$, we have the CDF of the Gumbel, Frechet, and the negative CDF of the Weibull distributions. Thus, we have established the following extreme value model:

1. Model 1: $\varsigma, \beta$, and $\kappa$ are the constant values

2. Model 2: $\varsigma$ and $\beta$ are the constant values; $\kappa=0$

3. Model 3: $\varsigma=a+b^{*}$ year, $\beta$ represents the constant values; $\kappa=0$

4. Model 4: $\varsigma=c+d^{*}$ year, $\beta$ represents the constant values; $\kappa=0$

5. Model 5: $\varsigma$ is the constant value, $\beta=\exp \left(a+b^{*}\right.$ year $), \kappa$ is the constant value

6. Model 6: $\varsigma$ is the constant value, $\beta=\exp \left(a+b^{*}\right.$ year $), \kappa=0$
7. Model 7: $\varsigma=a+b^{*}$ year, $\beta=\exp \left(c+d^{*}\right.$ year $), \kappa$ is the constant value

8. Model 8: $\varsigma=a+b^{*}$ year, $\beta=\exp \left(c+d^{*}\right.$ year $), \kappa=0$

In this section, we analyze special case models 1 and 2. We used a likelihood ratio test, i.e., if $L_{1}$ and $L_{2}$ are the maximum likelihood values for models 1 and 2 , then $\lambda=-2 \log \left(L_{2} / L_{1}\right)$. We considered one degree of freedom of the chi-squared distribution for estimation purposes (degrees of freedom based on various adjustments of the parameters). In hypothesis testing problems, approximation of real-world data was used instead of infinity. Therefore, at a 5\% significance level, the two-parameter model 2 (assumption-2 $\log \left(L_{2} / L_{1}\right)<$

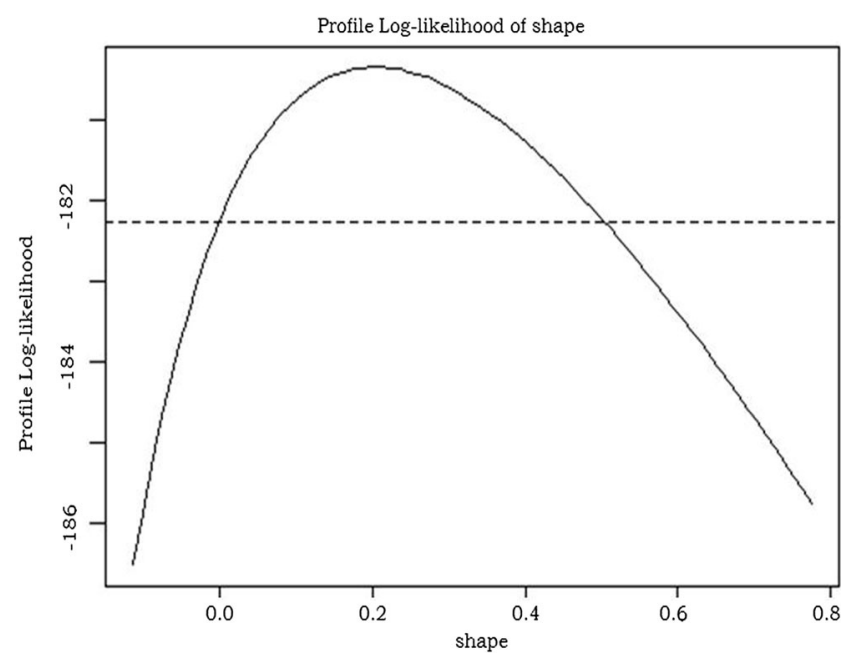

Fig. $5 K$ parameter log-likelihood profile in model 1 regarding Beitashan 

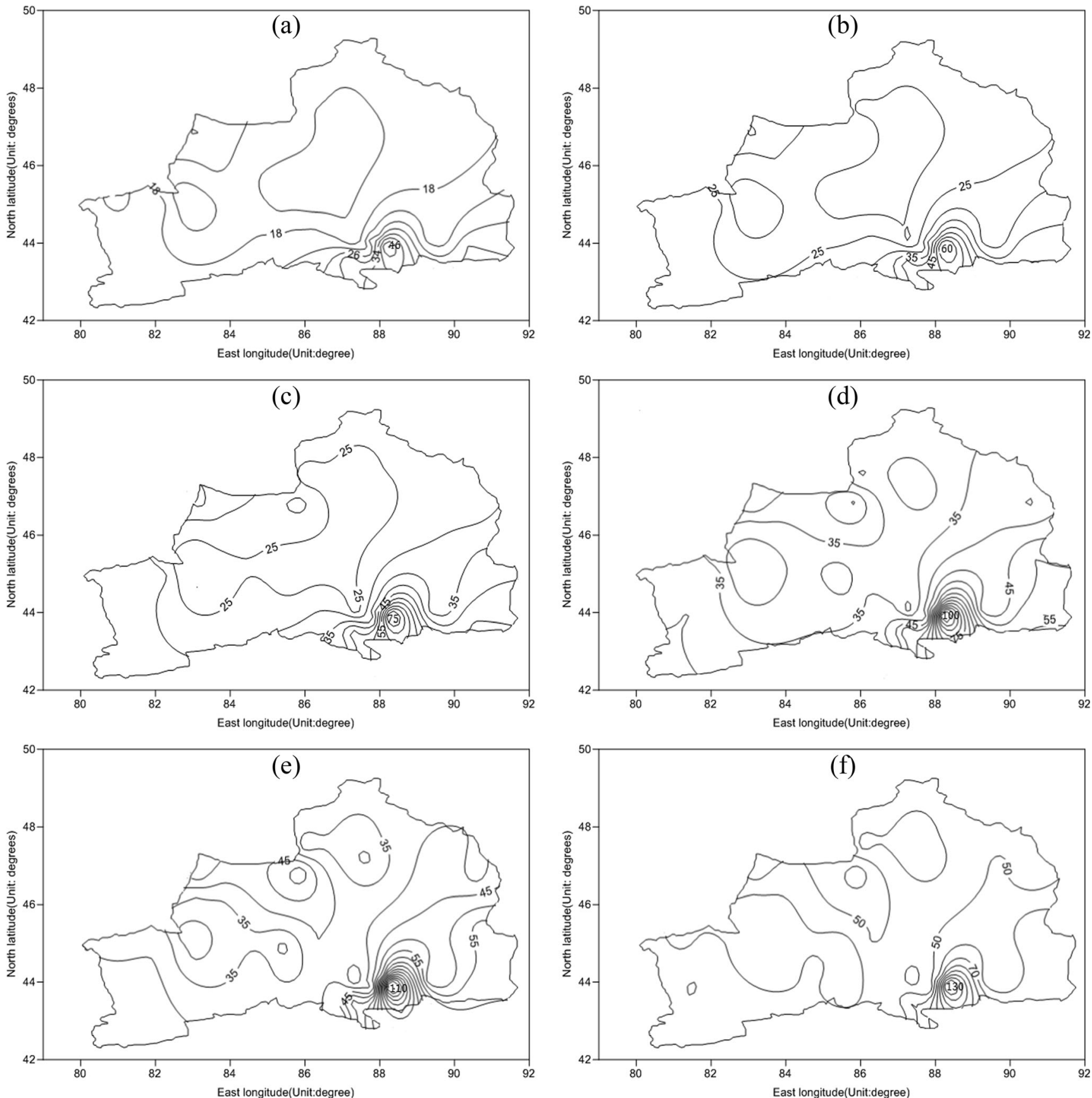

Fig. 6 Spatiotemporal distribution of the estimated maximum daily precipitation over northern Xinjiang for various reoccurrence intervals (a 2 years, $\mathbf{b}$ 5 years, $\mathbf{c} 10$ years, $\mathbf{d} 30$ years, e 50 years, $\mathrm{f} 100$ years) (unit: $\mathrm{mm} /$ day)

$x_{1,0.95}^{2}=3.84$ ) was preferred. In practice, because the annual maximum values were not completely independent, this description would be most effective.

Figure $2 \mathrm{a}-\mathrm{d}$ shows that the annual maximum daily rainfall and time (years) have a certain line trend. We built models 3 and 4 to explain this problem, approaching three to four parameters. Similarly, we used a standard of likelihood ratio test to determine whether the trends described in models 3 and 4 were significant. Furthermore, we conducted a comparison of fitting results by means of a QQ plot and density map. There is a quantile forecasting QQ plot (Fig. 4) of the fitted model. For example, to test the fit of model 1, we depicted the sort value (in ascending order) of the annual maximum daily rainfall observed by the expected percentile $y_{i}$, which was obtained by $F\left(y_{i}\right)=(i-0.375) /$ 
Fig. 7 Mean residual life plot of Urumqi precipitation data.

Thresholds $(u)$ vs. mean excess precipitation (unit: $\mathrm{mm}$ )

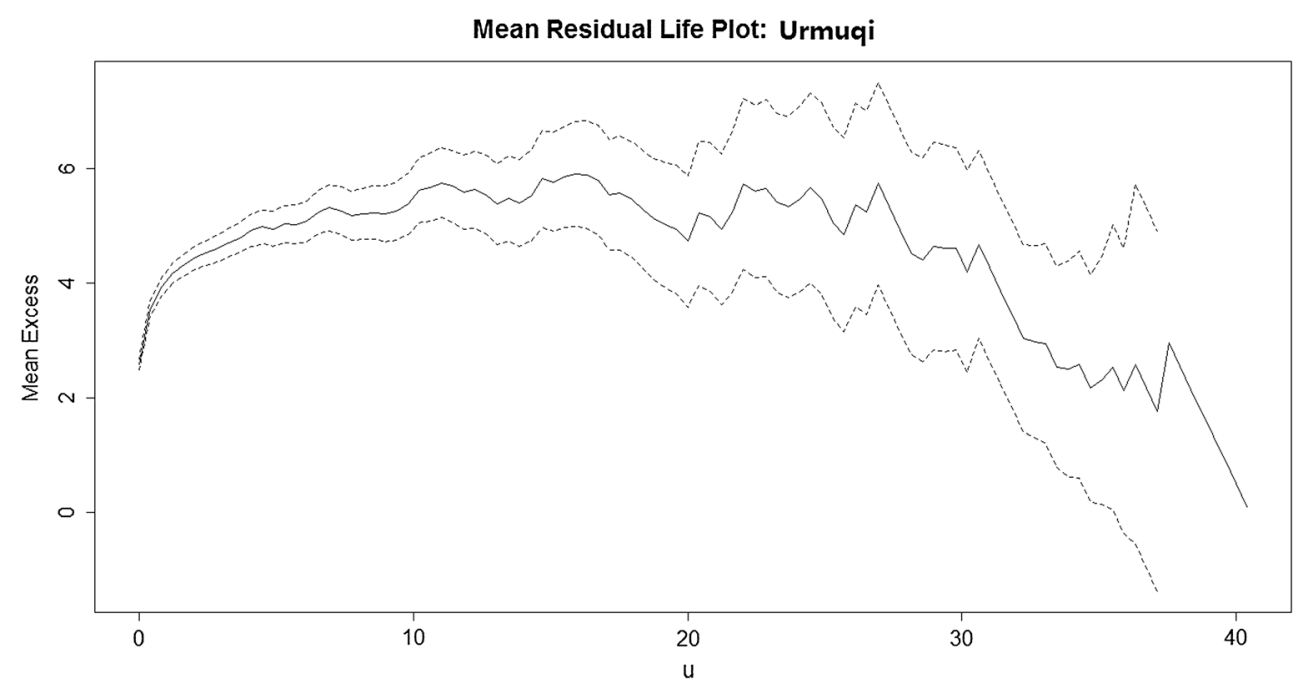

$(n+0.25)$ simulation, where $F$ is in Eq. (1) of the accumulation function. Similarly, concerning the fit for model 2, we depicted the sort value following the same procedure described for model 1 . The density function was graphed to compare models and non-parametric model fitting density.

Among those, the models 1 and 2 fitting density computations are

$f(x)=\frac{1}{\beta}\left(1+\kappa \frac{x-\varsigma}{\beta}\right)^{-\frac{1}{\kappa+1}} \times \exp \left\{-\left(1+\kappa \frac{x-\varsigma}{\beta}\right)^{\kappa}\right\}$

and

$f(x)=\frac{1}{\beta} \exp \left(-\frac{x-\varsigma}{\beta}\right) \times \exp \left\{-\exp \left(-\frac{x-\varsigma}{\beta}\right)\right\}$. respectively.

Non-parametric estimation was calculated using the kernel method (Silverman 1986). Based on the above analysis, we determined the best model, thus calculating return periods. A T-year return period using $x_{T}$ represents the maximum value of $t$ years (annual maximum daily rainfall). The calculation of the return period including $F\left(x_{T}\right)=1-\frac{1}{T}$ from model 1 yields the expression

Similarly, the $T$ from model 2 is
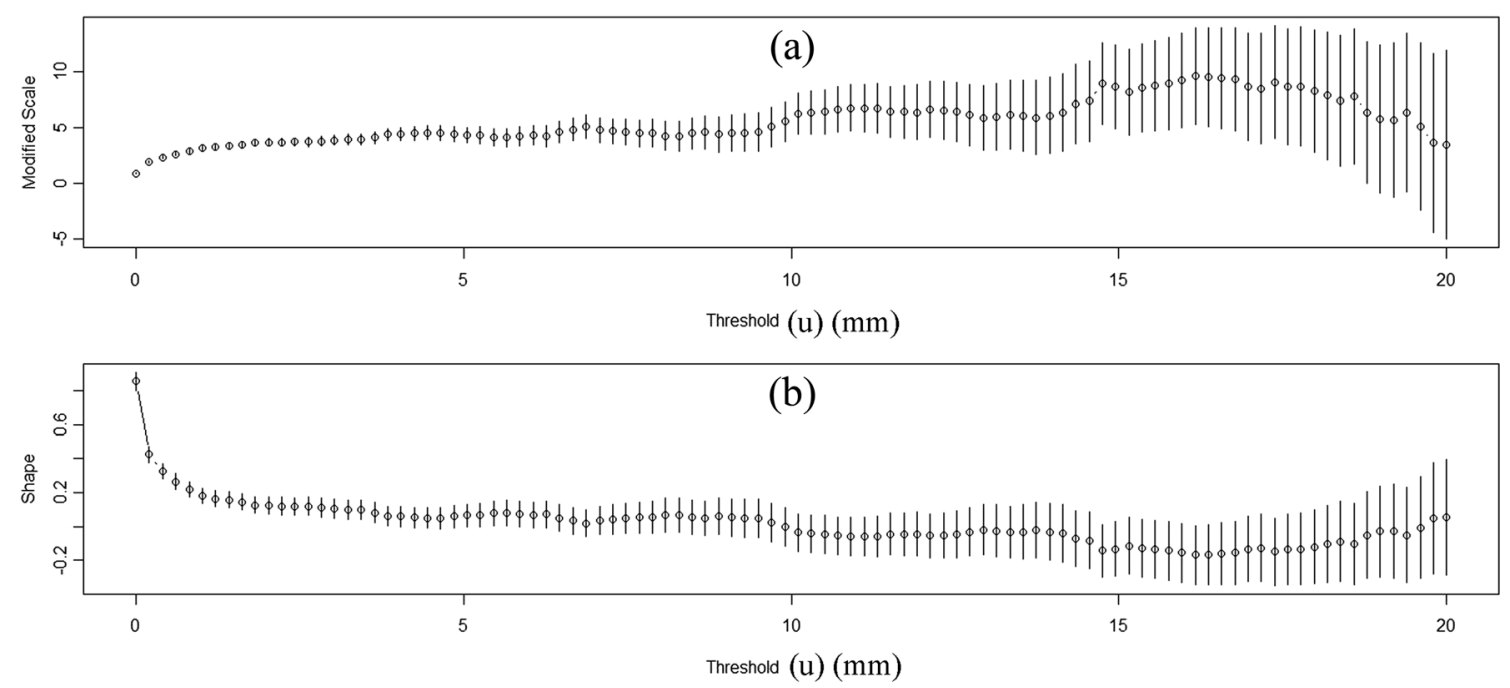

Fig. 8 a, b GPD fits for a range of 100 thresholds from 0 to $20 \mathrm{~mm}$ for the Urumqi precipitation dataset 
Fig. 9 GPD fit diagnostic plots for Urumqi precipitation data using a threshold of $10 \mathrm{~mm}$
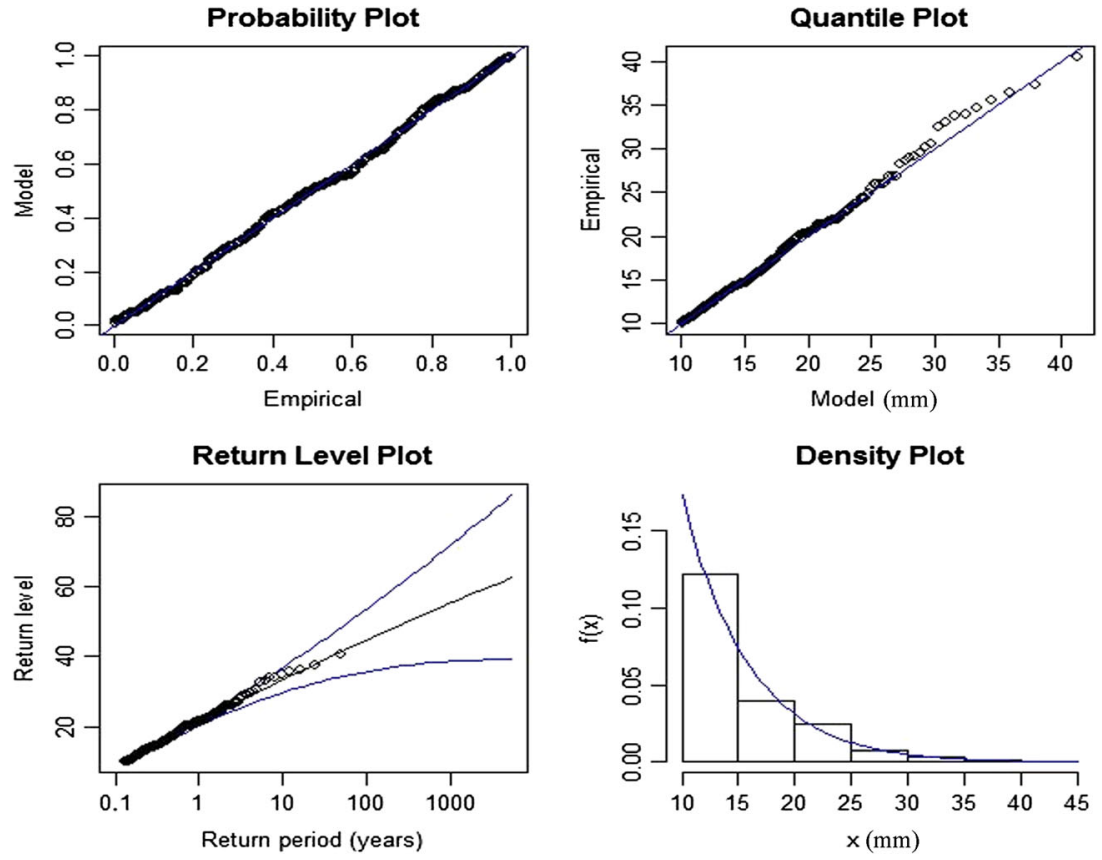

We entered $\varsigma, \beta$, and $\kappa$ values into Eqs. (3) and (4) to calculate $T$ values in models 1 and 2 .

Confidence interval estimates are usually based on Delta or resampling techniques. Here, we used the profile likelihood method, which is generally considered superior to any other existing method (Kupferberg et al. 2012). The profile likelihood $L_{p}\left(x_{T}\right)$ calculation is given by

$L_{p}\left(x_{T}\right)=\max _{\beta, \kappa} L\left(x_{T}, \beta, \kappa\right)$.

For $x_{T}$ of $100(1-\alpha) \%$, the confidence interval is set via

$\left\{\theta: 2 \log \left(\frac{L(\varsigma, \beta, \kappa)}{L_{p}(\theta)}\right)\right\}<\chi_{1,1-\alpha}^{2}$

Here, $\chi_{1,1-\alpha}^{2}$ expresses the $100(1-\alpha) \%$ quantile of the chi-squared distribution of freedom.

We selected sites at Beitashan, Yining, Urumqi, and Habahe to analyze this method. Let $L_{i}$ represent the maximum likelihood value of models 1 through 4 , where $i=1,2,3,4$. Using model 1 estimates for Beitashan, we obtained $\varsigma=17.14, \beta=6.77, \kappa=0.20$, and $-2 \log L_{1}=360.68$. Analogous model 2 estimates were $\varsigma=18.23, \beta=7.02$, and $-2 \log L_{2}=362.95$. Thus, there were analog effects for model 2 but not for model 1. Figure 3 certifies the above conclusion. Figure 5 further illustrates the problem in which $\kappa=0$ is not included in the confidence interval.
We used models 3 and 4 to simulate Beitashan's annual maximum daily rainfall. This produced $-\log L_{3}=179.73-$ $\log L_{3}=179.73$ and $-\log L_{4}=180.06$, then $-\log 2 L_{3}=$ 359.46 and $-\log 2 L_{4}=360.12,-\log 2 L_{1} / L_{3}<3.84$, and $\log 2 L_{2} / L_{4}<3.84$. We did not find that the time (year) of models 3 and 4 responded to significant trends. Models beyond 3 and 4 did not provide a significant fit. We compared models $1-8$ in the same manner. We found no significant response to changing trends. Therefore, we concluded that model 1 was the most suitable (GEV distribution). The above analysis matches findings at other sites. Table 3 presents four examples of the site selection model, standard error, parameter values, and the Kolmogorov-Smirnov test results. Table 4 shows the example 5 estimate of the return period of the site $T=2.5,10,30,50$, and 100 .

The same approach was used for data related to 33 other sites, most of which were in accordance with model 1. Using model 1 for extreme precipitation (annual maximum daily rainfall), 37 meteorological stations in North Xinjiang gave $T=2.5,10,30,50$, and 100 years. Figure $6 \mathrm{a}-\mathrm{f}$ shows kriging interpolation for $2,5,10,30,50$, and 100-year spatiotemporal distributions of return periods. The distribution map of annual maximum daily rainfall revealed similar annual averages of both rainfall and precipitation in the mountains. Figure 6 shows that for $T=2$ years, future precipitation is mostly greatly in excess of $18 \mathrm{~mm} /$ day. For $T=5$ and 10 years, precipitation maxima in the Tianshan Mountains surpass $25 \mathrm{~mm} /$ day. For $T=30$ and 50 years, most maxima are $>35 \mathrm{~mm} /$ day. For $T=100$ years, the maxima are $<90 \mathrm{~mm} /$ day. 

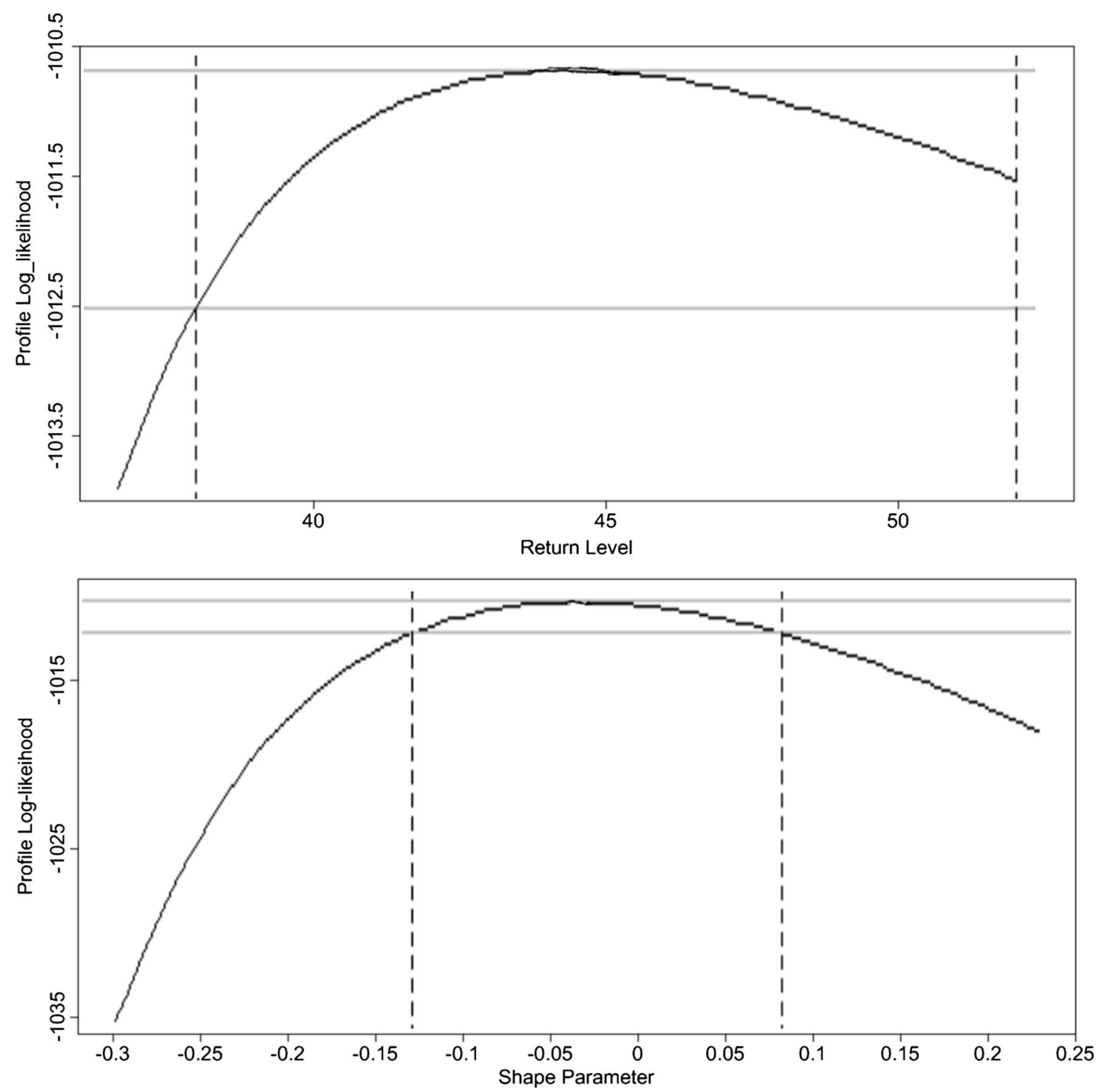

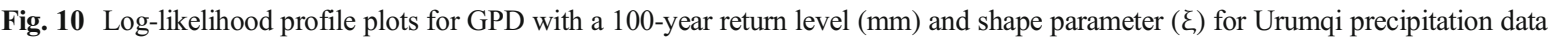

\subsection{Generalized Pareto distribution (GPD) fitting}

In contrast to GEV distribution, GPD describes the distribution of events exceeding a certain threshold (e.g., $>20 \mathrm{~mm}$ of precipitation). This solves the problem of insufficient extreme precipitation data while increasing the use of existing information.
However, in GPD fitting, determination of the threshold value is a key issue and major step. The mean residual life plot has served as a model to estimate an exploratory technology (Fig. 7). In this diagram, an approximately linear growth with largeamplitude fluctuations is observed. Appropriate thresholds are believed to occur in the linear growth trend at the end of the

Table 3 Best-fitted models and parameter estimates

\begin{tabular}{|c|c|c|c|c|c|}
\hline \multirow[t]{2}{*}{ Sites } & \multirow[t]{2}{*}{ Best model } & \multicolumn{3}{|c|}{ Parameter estimation } & \multirow[t]{2}{*}{$\mathrm{K}-\mathrm{S}$ tes } \\
\hline & & $\varsigma($ s.e. $)$ & $\beta($ s.e. $)$ & $\kappa($ s.e. $)$ & \\
\hline Beitashan & Model 2 & $17.33(1.12)$ & $7.33(0.88)$ & & 0.14 \\
\hline Habahe & Model 1 & $14.05(0.79)$ & $5.03(0.60)$ & $0.10(0.09)$ & 0.15 \\
\hline Urumuqi & Model 1 & $17.21(1.40)$ & $8.85(1.03)$ & $-0.26(0.11)$ & 0.08 \\
\hline Yining & Model 1 & $18.13(0.83)$ & $5.24(0.63)$ & $0.12(0.10)$ & 0.15 \\
\hline
\end{tabular}


Table 4 Return level estimates for $T=2,5,10,30,50,100$ years (unit: $\mathrm{mm} /$ day)

\begin{tabular}{lllllll} 
Sites & \multicolumn{1}{l}{ Return period level $x_{T}(95 \%$ confidence interval $)$} & & & \\
\cline { 2 - 6 } & $T=2$ & $T=5$ & $T=10$ & $T=30$ & $T=50$ & $T=100$ \\
\hline Beitashan & $19.72(17.3,22.52)$ & $29.02(25.06,35.13)$ & $36.47(30.64,47.93)$ & $50.13(39.31,75.02)$ & $57.50(43.29,91.98)$ & $68.75(48.67,120.53)$ \\
Habahe & $15.92(14.23,17.85)$ & $22.19(19.63,25.84)$ & $26.75(23.25,33.09)$ & $34.32(28.61,46.52)$ & $38.08(31.00,54.03)$ & $43.47(34.13,65.80)$ \\
Urumuqi & $20.30(17.47,23.23)$ & $28.18(25.22,31.46)$ & $32.25(29.22,36.86)$ & $37.05(33.68,43.96)$ & $38.81(35.18,47.04)$ & $40.83(36.78,51.07)$ \\
Yining & $20.09(18.29,22.14)$ & $26.77(24.00,30.74)$ & $31.73(27.90,38.92)$ & $40.15(33.76,54.08)$ & $44.41(36.39,62.90)$ & $50.61(39.88,76.95)$ \\
\hline
\end{tabular}

curve and $\sim 10 \mathrm{~mm}$ was optimum here. The $95 \%$ confidence interval is shown by a dashed line.

Alternatively, it is possible to calculate each time with different $u$ threshold values. Changes can be estimated by determining stability in terms of scale and shape parameters of the maximum likelihood, as shown in Fig. 8. Similarly, the linear trend of the curve begins fluctuating toward the end of the defined threshold (10 mm). Figure 7 shows a statement conclusion, drawn from studies on threshold points of extreme precipitation $(10 \mathrm{~mm})$ in Urumqi.

We used the 10-mm threshold (the GPD fitting precipitation data from sites in Urumqi), diagnostic charts, and histograms to represent the observed data and curve-fitting model (Fig. 9). The regression level with $95 \%$ confidence interval is shown in Fig. 9. Over the entire period, there were a total of 371 days when precipitation exceeded the 10-mm threshold; with an annual average of $7.42 \mathrm{~mm}$. Estimation of scale parameter value was $\sigma$ $=5.77$ with a standard deviation of 0.43 . The estimated shape parameter was $\xi=-0.03$ with a standard deviation of 0.05 . The tail of the density map effectively shows the distribution of fitting observational data and models. The regression level is presented as a nonlinear curve, with its upper and lower curves on either side of the $95 \%$ confidence interval. Figure 10 depicts the configuration of the log-likelihood estimation, fitting the 100-year GPD T. $T=100$-year corresponding to levels of $44.61 \mathrm{~mm}$ (38.20 left, 52.34 right), and the MLE estimate is $\xi=-0.03$ $(-0.13,0.09)$.

Estimates using the GPD and GEV fitting $T$ levels for Urumqi are shown in Table 4, demonstrating similar fitting results for GPD and GEV. For shorter $T$, such as 2 and 5 years for estimated precipitation levels, GPD results at all sites were slightly better than those of GEV. For $T=10$ years, the two methods showed very similar estimations, and for 30 years and longer, GPD was frequently greater than with GEV concerning Urumqi. For a 100- year $T$, precipitation reached $44.62 \mathrm{~mm}$ /day for GPD, greater than GEV at $40.83 \mathrm{~mm} /$ day, shown in Table 5. Similarly, results were gathered at other sites. GPD was much higher at most sites fitting the GEV level regression estimation. Based on precipitation data using the GEV distribution and GPD for 37 sites fitting the precipitation event, we obtained the parameter estimates; results differed slightly but remained similar overall. This is not covered in detail here.

\section{Summary}

We applied GEV and GPD statistical distribution functions to fit the output of precipitation extremes with different $T$, to diagnose the risk of flood variability and associated spatial patterns in northern Xinjiang, China. Important results were obtained, as follows:

1. GEV extreme value modeling yielded the best results, proving to be extremely valuable. Through example analysis for extreme precipitation models, the GEV statistical model was superior for favorable analog extreme precipitation. The risk of flooding in northern Xinjiang has changed markedly. Aridity in the region has decreased prominently. CDD decreased at a rate of 1.7 days/10 years, while consecutive wet days increased at a lower rate of 0.1 days/ 10 years. This situation accords with the view that the climate in Xinjiang has been changing from warm-dry to warm-wet in recent years.

2. The GPD model calculation results reflect annual precipitation. The precipitation data found using a broad value theory distribution (GEV) and broad GPD for 37 sites during the precipitation event were close to the parameter estimates, and the results showed different values. For most

Table 5 Return level estimates for $T=2,5,10,30,50,100$

Distributions Return period level $x_{T}$ (95\% confidence interval)

\begin{tabular}{lllllll} 
& $T=2$ & $T=5$ & $T=10$ & $T=30$ & $T=50$ & $T=100$ \\
\hline GPD & $24.95(23.55,26.76)$ & $29.77(27.67,32.99)$ & $33.32(30.49,38.10)$ & $38.81(34.46,45.24)$ & $41.30(36.12,48.29)$ & $44.62(38.20,52.35)$ \\
GEV & $20.30(17.47,23.23)$ & $28.18(25.22,31.46)$ & $32.25(29.22,36.86)$ & $37.05(33.68,43.96)$ & $38.81(35.18,47.04)$ & $40.83(36.78,51.07)$ \\
\hline
\end{tabular}


of the estimated sites 2 and 5 -year $T$ for precipitation levels, GPD results were slightly greater than those of GEV. For $T=10$ years, the two methods were very similar. For $T=30$ years, and the regression cycle, the GPD fitting estimated much greater values than GEV. After more than 30 years, we found that the simulation results of the GPD model are better than that of the GEV model by linear regression. The GPD shows evidence of significant positive trends, indicating that the significance of the extreme precipitation in northern Xinjiang is sensitive to the method used. In addition, GDP would be able to predict the return value of this extreme rainfall event at a specific time in the future.

3. Based on the chosen models, we have provided return levels of the extreme precipitation (including intervals of return levels) for $T=2,5,10,30,50$, and 100 years. From the spatiotemporal distribution diagram of extreme rainfall, extreme precipitation is increasing in northern areas, particularly in the mountainous areas of North Azerbaijan. For example, Tianchi shows evidence of increased significance trends in the southeast of the investigated area. In the northern Xinjiang area, precipitation values, extreme rainfall, and flood disaster events were compared. The study found that extreme precipitation that reaches a certain limit value level will cause a flood disaster. Therefore, predicting future extreme precipitation may aid in predictions of flood disasters. The results of this study may serve as a useful reference for future studies regarding early-warning systems for flood disasters.

\begin{abstract}
Acknowledgments This research study was supported by the National Natural Science Foundation of China (Grant No. 41471140, 41671158) and Liaoning Province Outstanding Youth Program (Grant No. LJQ2015058). The authors would like to acknowledge all the experts who contributed to the building of the model and the formulation of the strategies herein. We sincerely thank the Institute of Geographic Sciences and Natural Resources Research, CAS.
\end{abstract}

\section{Compliance with ethical standards}

Conflict of interest The authors declare that they have no conflict of interest.

Open Access This article is distributed under the terms of the Creative Commons Attribution 4.0 International License (http:// creativecommons.org/licenses/by/4.0/), which permits unrestricted use, distribution, and reproduction in any medium, provided you give appropriate credit to the original author(s) and the source, provide a link to the Creative Commons license, and indicate if changes were made.

\section{References}

Alpert P, Ben-Gai T, Baharad A, Benjamini Y, Yekutieli D, Colacino M (2002) The paradoxical increase of Mediterranean extreme daily rainfall in spite of decrease in total values. Geophys Res Lett 29(11):31-1-31-4

Arnell N W (1999) Climate change and global water resources. 9(99): S31 - S49

Bonacci O (1991) The influence of errors in precipitation measurements on the accuracy of the evaporation measurements performed by a class A evaporation pan. Theor Appl Climatol 43(4):181-183

Burt TP, Worrall F, Howden NJK, Anderson MG (2015) Shifts in discharge-concentration relationships as a small catchment recovers from severe drought. Hydrol Process 29(4):498-507

Christensen N, Lettenmaier DP (2006) A multimodel ensemble approach to assessment of climate change impacts on the hydrology and water resources of the Colorado River basin. Hydrol Earth Syst Sci Discuss 3(6):3727-3770

Du TJ (2007) The fourth assessment report of the intergovernmental panel on climate change (ipcc). Political Science and Politics 36(03):423-426

Easterling DR (2000) Climate extremes: observations, modeling, and impacts. Science 289(5487):2068-2074

Embrechts P, Klüppelberg C, Mikosch T (1997) Modelling Extremal Events 71(2):183-199

Ge Q, Kong Q, Xi J, Zheng J (2016) Application of UTCI in China from tourism perspective. Theor Appl Climatol 1-11. doi:10.1007/ s00704-016-1731-z

Hosking JRM, Wallis JF (1987) Parameter and quantile estimation for the generalized pareto distribution. Technometrics 29(3):339-349

Hosking JRM, Wallis JF (2005) Regional frequency analysis: an approach based on L-moments. Cambridge University Press, Cambridge

Kupferberg SJ, Palen WJ, Lind AJ, Bobzien S, Catenazzi A, Drennan J (2012) Effects of flow regimes altered by dams on survival, population declines, and range-wide losses of California river-breeding frogs. Conserv Biol 26(3):513-524

Li X, Jiang F, Li L, Wang G (2011) Spatial and temporal variability of precipitation concentration index, concentration degree and concentration period in Xinjiang, China. Int J Climatol 31(11):1679-1693

Li J, Zhang Q, Chen YD, Singh VP (2015) Future joint probability behaviors of precipitation extremes across China: spatiotemporal patterns and implications for flood and drought hazards. Global \& Planetary Change 124:107-122

Lodh A, Raghava R (2014) Retracted article: spatio-temporal variability of soil moisture-precipitation feedback in Indian summer monsoon regime. Theor Appl Climatol 118(1-2):365-365

Middelkoop H, Daamen K, Gellens D, Grabs W, Kwadijk JCJ, Lang H (2001) Impact of climate change on hydrological regimes and water resources management in the Rhine basin. Clim Chang 49(1):105128

Moynagh J, Schimmel H (1999) Tests for BSE evaluated. Nature 400(6740): 105

Norrant C, Douguédroit A (2006) Monthly and daily precipitation trends in the Mediterranean (1950-2000). Theor Appl Climatol 83(1-4): 89-106

Reilly J, Tubiello F, McCarl B, Abler D, Darwin R, Fuglie K (2003) U.S. agriculture and climate change: new results. Clim Chang 57(1):4367

Ren G, Wu H, Chen Z (2000) Spatial patterns of change trend in rainfall of China. Quarterly Journal of Applied Meteorlolgy 11(3):322-330

Saghafian B, Golian S, Ghasemi A (2014) Flood frequency analysis based on simulated peak discharges. Nat Hazards 71(1):403-417

Silverman BW (1986) Density estimation for statistics and data analysis 26. CRC press

Vörösmarty CJ, McIntyre PB, Gessner MO, Dudgeon D, Prusevich A, Green P (2010) Global threats to human water security and river biodiversity. Nature 467(7315):555-561 
Yan Z, Yang C (2000) Geographic patterns of extreme climate changes in China during 1951 - 1997. Climatic and Environmental Research 5: 267-271

Zhang Y, Wei W, Jiang F, Liu M, Wang W (2012) Trends of extreme precipitation events over Xinjiang during 1961-2008. J Mt Sci 30(4):417-424
Zhang Y, Ge Q, Liu M (2015) Extreme precipitation changes in the semiarid region of Xinjiang, Northwest China. Adv Meteorol 2015:1-7

Zhang YF, Zhang ZW, Gong YH (2016) Research on precipitation spatial-temporal regulation and drought predicition in middlelower han river basin. Environ Eng 34(2):150-154 